\title{
KARAKTERISTIK REMAJA PUTRI YANG MENGALAMI KEHAMILAN YANG TIDAK DIINGINKAN KOTO BARU SIMALANGGANG KECAMATAN PAYAKUMBUH
}

\author{
Siti Khadijah \\ Poltekkes Kemenkes Padang \\ sofyangadis@gmail.com
}

\begin{abstract}
ABSTRAK
Kasus remaja dengan kehamilan yang tidak diinginkan di kecamatan Payakumbuh tahun 2013 berjumlah 32 orang. Tujuan penelitian ini adalah untuk menganalisis karakteristik introvert, ekstrovert dan ambivert remaja putri yang mengalami kehamilan yang tidak diinginkan. Jenis penelitian yaitu kualitatif dan desain penelitian adalah penelitian deskriptif. Penelitian dilakukan di Nagari Koto Baru Simalanggang. Teknik pengambilan sampel adalah total sampling sebanyak 6 orang. Instrumen penelitian adalah peneliti sendiri dengan menggunakan pedoman wawancara. Hasil penelitian menunjukkan bahwa diketahui ada 6 remaja putri yang mempunyai karakteristik introvert dalam menjawab pertanyaan pertama dan pertanyaan kedua. Diketahui 4 remaja putri mempunyai karakteristik estrovert dan 2 remaja putri yang mempunyai karakteristik introvert dalam menjawab pertanyaan ketiga. Diketahui 4 remaja putri mempunyai karakteristik ekstrovert dan 2 remaja putri mempunyai karakteristik introvert dalam menjawab pertanyaan keempat. Diketahui ke 6 remaja tersebut mempunyai karakteristik ekstrovert dalam menjawab pertanyaan kelima dan pertanyaan ke 6. Dapat disimpulkan bahwa remaja putri yang mengalami kehamilan yang tidak diinginkan mempunyai karakteristik introvert, ekstrovert dan tidak ada remaja putri yang mengalami karakteristik ambivert. Dan diharapkan kepada tenaga kesehatan agar dapat memberikan penyuluhan tentang kesehatan reproduksi yang lebih komprehensif dan memberikan pendidikan seks dini pada remaja.
\end{abstract}

\section{Kata Kunci : Karakteristik; Kehamilan; Remaja}

\begin{abstract}
Case teenagers with unwanted pregnancies in Payakumbuh at 2013 amounted to 32 people. The purpose of this study was to analyze the characteristics of an introvert, extrovert and ambivert young women experiencing an unintended pregnancy. This type of research is qualitative research,the design was a descriptive study. The study was conducted in Kecamatan Payakumbuh. The sampling is total sampling as many as six people. The research was using interview guide. The results showed that in mind there are six young women who have the characteristics of an introvert in answering the first question and the second question. Given that 4 girls have the characteristics estrovert and 2 girls have introverted characteristics in answering the third question. Given that 4 girls having extrovert characteristics and 2 girls had the characteristics of an introvert in answering the fourth question. 6 teens are known to have characteristics extrovert in answering fifth and sixth questions. It can be concluded that girls who experience an unintended pregnancy has the characteristics of an introvert, extrovert and no girls who had the characteristics ambivert. It was expected that health professionals in order to provide education on reproductive health and provide more comprehensive sex education early in teenagers.
\end{abstract}

Keywords: Characteristics; Pregnancy; Teeneger

(Diterima: 19-01-2017, Disetujui:29-05-2017) 


\section{PENDAHULUAN}

Masa remaja, banyak remaja mengalami perubahan fisik maupun secara psikologis, sehingga mengakibatkan perubahan sikap dan tingkah laku, seperti mulai memperhatikan penampilan diri, mulai tertarik dengan lawan jenis, berusaha menarik perhatian dan muncul perasaan cinta, yang kemudian akan timbul dorongan seksual. Saat ini, banyak remaja yang kurang mendapatkan penerangan mengenai kesehatan reproduksi. Pengetahuan remaja tentang kesehatan reproduksi masih sangat rendah. Salah satu masalah pada masa remaja adalah perilaku yang berkaitan dengan seks pranikah dan dapat terjadinya kehamilan yang tidak diinginkan. Dampak dari seks bebas adalah hamil diluar nikah, merasa terancam dengan kehamilan yang tidak dinginkan, maka jalan pintasnya mereka melakukan aborsi.

Hasil penelitian diIndonesia pada tahun 2005, membuktikan bahwa remaja secara terbuka menyatakan telah melakukan seks pranikah diantaranya di Jabotabek 51\%, Bandung 54\%, Surabaya 47\%, dan Medan $52 \%$. Dari 2,3 juta kasus aborsi diantaranya $15-20 \%$ dilakukan oleh remaja, hal ini dipengaruhi oleh faktor yaitu hubungan seksual yang berakibat kehamilan diluar nikah, akses terhadap pendidikan dan pekerjaan, ketidaksetaraan gender, kekerasan seksual dan pengaruh media massa maupun gaya hidup .

Pada tahun 2008, di Jakarta dari 405 kehamilan yang tidak direncanakan, 95\% dilakukan oleh remaja usia 15-25 tahun. Survey KOMNAS Perlindungan Anak di 33 Provinsi menyimpulkan bahwa $97 \%$ remaja SMP dan SMA pernah menonton film porno, 93,7\% remaja SMP dan SMA pernah melakukan genital stimulation (meraba alat kelamin) dan oral seks, $62,7 \%$ remaja SMP dan Sma tidak perawan, dan $21,2 \%$ remaja mengaku pernah aborsi. Data Pusat Keluarga Berencana Indonesia (PKBI) pada tahun 2006 menunjukkan bahwa kisaran umur melakukan hubungan seks pranikah pada umur 13-18 tahun. Pada daerah Kabupaten 50 Kota tahun
2013, kasus remaja dengan kehamilan yang tidak diinginkan (KTD) berjumlah 200 orang. Dari 200 orang remaja putri dengan kehamilan tidak diinginkan, kecamatan Payakumbuh termasuk salah satu penyumbang angka tertinggi no. 2 untuk kejadian kehamilan tidak dinginkan (KTD) yaitu 32 orang. Dikecamatan Payakumbuh remaja putrid yang mengalami kehamilan tidak diinginkan yaitu di Nagari Sungai Baringin ada 4 remaja putri, Nagari Piobang ada 3 remaja putri, Nagari Koto Baru Simalanggang ada 6 remaja putri, Nagari Simalanggang ada 5 remaja putri, Nagari Koto tangah Simalanggang ada 4 remaja putri, Nagari Taeh Baruah ada 5 remaja putri dan Nagari Taeh Bukik ada 5 remaja putri .

Disamping studi dokumentasi juga dilakukan wawancara singkat pada tanggal 2 Januari 2014 kepada Bidan yang bertugas di wilayah kerja Puskesmas Koto Baru Simalanggang, menyatakan bahwa remaja yang mengalami kehamilan tidak dinginkan berjumlah 32 orang, yang mana di Nagari Koto Baru Simalanggang terdapat 6 remaja putri yang mengalami kehamilan tidak diinginkan yaitu 3 orang remaja berada di Jorong Koto Baru, 2 orang remaja berada di Jorong Tabek panjang dan 1 orang remaja putri berada di Jorong Parumpuang. Sementara dampak psikologis remaja putri terhadap kehamilan tidak diinginkan (KTD) di wilayah ini belum diketahui dengan pasti. Karakteristik diperlukan untuk mengenali kepribadian seseorang, menurut Carl G. Jung, menggolongkan tingkah laku atau karakteristik psikologis yaitu Introvert, Ekstrovert dan Ambivert (Wirawan, 2000: 84). Hasil penelitian Latifah Husaeni yang berjudul Depresi Pada Remaja Putri Yang Hamil Diluar Nikah pada tahun 2010, menyimpulkan bahwa sebagian besar remaja putri yang hamil diluar nikah mengalami depresi berat yaitu seperti terpuruk, menangis, selera makan kurang, berat badan menurun dan lain-lain.

Berdasarkan hasil wawancara awal yang dilakukan terhadap 6 orang remaja putri yang berada di Jorong Koto Baru, dan Jorong 
Tabek panjang dan Jorong Parumpuan pada tanggal 25 januari 2014 yang mana remaja putri tersebut terlihat mengalami gangguan psikologis terhadap kejadian kehamilan yang tidak diinginkan. Sehubungan dengan hal di

\section{METODE PENELITIAN}

Subjek dalam penelitian ini adalah remaja putri yang mengalami kehamilan yang tidak diinginkan di Nagari Koto Baru Simalanggang Kecamatan Payakumbuh Kab.Lima Puluh Kota tahun 2014 yang berjumlah enam orang. Jenis penelitian yang digunakan yaitu penelitian kualitatif dimana prosedur penelitian yang menghasilkan data deskriptif berupa kata-kata tertulis atau lisan

\section{HASIL DAN PEMBAHASAN}

Penelitian ini dilakukan di Nagari Koto Baru Simalanggang Kecamatan Payakumbuh Kab.Lima Puluh Kota. Wilayah kerja Puskesmas Koto Baru Simalanggang terdiri dari tujuh Nagari, yang mana bidan diwilayah kerja puskesmas Koto Baru Simalanggang berjumlah 26 Bidan dan jumlah kejadian kehamilan yang tidak diinginkan pada remaja yang tertinggi berada di Nagari Koto Baru Simalanggang yaitu ada enam kasus. Nara sumber yang akan diwawancarai enam orang remaja putri yang mengalami kehamilan tidak diinginkan dengan enam buah item pertanyaan yang sama.

Tabel. 1. Daftar Responden Remaja Putri yang Mengalami Kehamilan yang Tidak Diinginkan

\begin{tabular}{|l|l|l|}
\hline No. & Responden & \multicolumn{1}{|c|}{ Keterangan } \\
\hline 1. & Ny. A & $\begin{array}{l}\text { Usia 16 tahun, hamil pada } \\
\text { usia 15 tahun }\end{array}$ \\
\hline 2. & Ny. R & $\begin{array}{l}\text { Usia 17 tahun, hamil pada } \\
\text { usia 16 tahun }\end{array}$ \\
\hline 3. & Ny. K & $\begin{array}{l}\text { Usia 18 tahun, hamil pada } \\
\text { usia 17 tahun }\end{array}$ \\
\hline 4. & Ny. V & $\begin{array}{l}\text { Usia 18 tahun, hamil pada } \\
\text { usia 17 tahun }\end{array}$ \\
\hline 5. & Ny. G & $\begin{array}{l}\text { Usia 17 tahun, hamil pada } \\
\text { usia 16 tahun }\end{array}$ \\
\hline 6. & Ny. F & $\begin{array}{l}\text { Usia 17 tahun, hamil pada } \\
\text { usia 16 tahun }\end{array}$ \\
\hline
\end{tabular}

atas, timbul pertanyaan bagaimana karakteristik remaja putri terhadap kehamilan tidak diinginkan (KTD) di Nagari Koto Baru Simalanggang, sehingga perlu dilakukan penelitian.

dari orang-orang dan perilaku yang dapat diamati (Sudigdo, 2011: 287). Desain penelitian yang digunakan adalah penelitian bersifat deskriptif yang bertujuan untuk mengetahui karakteristik remaja putri yang mengalami kehamilan tidak diinginkan (KTD) di Nagari Koto Baru Simalanggang Kecamatan Payakumbuh Kabupaten 50 Kota Tahun 2014.

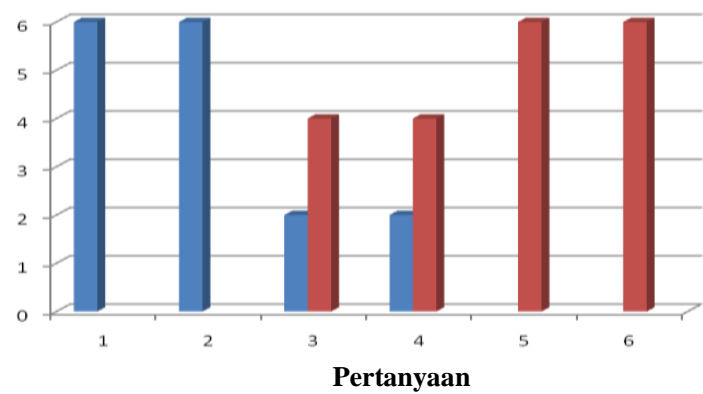

Gambar 1. Diagram batang karakter responden berdasarkan pertanyaan yang diajukan

\section{Karakteristik Introvert}

Hasil wawancara yang dilakukan pada 6 orang remaja putri yang mengalami kehamilan yang tidak diinginkan, diketahui 6 orang remaja putri yang kurang terbuka menceritakan siapa pertama kali mengetahui atau diberitahu kehamilan dan tanggapan orang tersebut.

Dari data peneliti berasumsi bahwa Ny. A memiliki karakteristik introvert karena $\mathrm{Ny}$. A tidak menjawab pertanyaan secara langsung dan nara sumber juga terlihat gugup dalam menjawab pertanyaan tersebut. Wawancara terhadap Ny.R, diperoleh hasil bahwa, suami Ny. R menginginkan kehamilannya. Ny. R memiliki karakteristik introvert karena dalam menceritakan orang yang pertama kali mengetahui kehamilannya karena narasumber hanya menjawab saat ditanya dan terlihat gugup saat ditanya. Peneliti juga sudah membuat suasana nyaman tapi narasumber tidak langsung menjawab dan terlihat gugup. 
Dari hasil wawancara terhadap Ny.K diperoleh hasil bahwa Ny. K mempunyai karakteristik introvert karena nara sumber dalam menjawab pertanyaan terlihat gugup dan lama dalam menjawab pertanyaan tersebut. Sedangkan hasil wawancara terhadap Ny.V tentang siapa yang mengetahui kehamilan serta tanggapannya, peneliti berasumsi bahwa Ny. $\mathrm{V}$ memiliki karakteristik inrovert karena dalam menjawab pertanyaan ini karena sewaktu bertanya narasumber terlihat berfikir dan lama menjawab pertanyaan tersebut dan seolaholah jawaban tersebut tidak benar.

Dari data hasil wawancara terhadap ny. G, diperoleh hasil bahwa suami Ny.G menginginkan kehamilan. Ny.G mempunyai karakteristik introvert karena dalam menceritakan siapa yang pertama kali mengetahui kehamilannya karena narasumber tidak menceritakan langsung tetapi hanya menjawab apabila diberi pertanyaan. Dari data wawancara terhadap Ny. F, diperoleh hasil bahwa Ny. F memiliki karakteristik introvert karena nara sumber terlihat agak gugup dalam menjawab pertanyaan yang diberikan.

Hasil wawancara tentang perasaan saat mengetahui hamil, diketahui enam orang remaja tidak terbuka. Data tersebut diketahui dari menganalisis jawaban nara sumber, dimana nara sumber tidak secara langsung menjawab pertanyaan dan berfikir sejenak dan nara sumber terlihat gugup. Dari hasil wawancara terhadap enam remaja putri, peneliti diperoleh hasil bahwa ke enam remaja tersebut memiliki karakteristik introvert dalam menceritakan perasaan disaat mengetahui kehamilannya. Karena narasumber tersebut tidak langsung menjawab pertanyaan yang diberikan dan terlihat gugup.

Hasil wawancara tentang kendala pada saat kehamilan diketahui dari enam orang remaja putri terdapat dua remaja putri yang tidak terbuka dalam menceritakan kendala pada saat kehamilan tersebut. Dari data hasil wawancara terhadap Ny.A dan Ny.R, diperoleh hasil bahwa kedua remaja tersebut memiliki karakteristik introvert dalam menjawab pertanyaan tentang kendala pada saat kehamilan, karena nara sumber hanya menjawab secara singkat saja, sehingga peneliti tidak mendapat jawaban yang sempurna.

Hasil wawancara tentang pemeriksaan kerumah bidan dan dengan siapa nara sumber pergi kerumah bidan tersebut. Diketahui dari enam orang remaja putri yang mengalami kehamilan yang tidak diinginkan, satu orang yang kurang terbuka menceritakan berapa kali nara sumber pergi kerumah bidan dan dengan siapa pergi kerumah bidan. Dari data hasil wawancara terhadap Ny.K, diperoleh hasil bahwa nara sumber tersebut memiliki karakteristik introvert dalam menjawab pertanyaan tentang berapa kali periksa kerumah bidan dan dengan siapa pergi periksa kehamilan, karena terlihat saja dari sikap nara sumber tersebut bingung dan gugup dalam menjawab pertanyaan tersebut.

Menurut teori yang terdapat ditinjauan pustaka, karakter introvert adalah karakteristik berdasarkan psikologis atau tingkah laku terutama dalam keadaan emosional atau konflik. Orang dengan kepribadian ini cenderung untuk menarik diri dan menyendiri. Ia pemalu dan lebih suka bekerja sendiri dilaboratorium atau perpustakaan daripada bekerja ditengah tengah orang banyak. (Wirawan, 2000;82-84)

Berdasarkan hasil penelitian dilapangan, diketahui remaja putri yang mengalami kehamilan yang tidak diinginkan memiliki karakter introvert, hal ini diketahui melalui hasil wawancara dan observasi langsung yang dilakukan peneliti, sehingga peneliti menganalisis bahwasanya hasil penelitian sesuai dengan teori yang terdapat ditinjauan pustaka yaitu remaja yang mengalami kehamilan yang tidak diinginkan kurang terbuka menceritakan siapa yang pertama kali mengetahui kehamilannya serta tanggapan orang tersebut, perasaan saat mengetahui kehamilannya, kendala dalam kehamilan serta apakah pernah pergi periksa kerumah bidan apa tidak. 
Oleh karena itu, peneliti menganalisis bahwasanya faktor yang mempengaruhi remaja tersebut tidak terbuka dalam menjawab pertanyaan yaitu karena usia remaja tersebut yang sangat masih muda untuk hamil yaitu umur 15 - 17 tahun, serta ia juga merasa malu dengan kehamilan yang dijalaninya karena kehamilannya terjadi diluar pernikahan, terlebih lagi pandangan dan anggapan masyarakat yang memandang rendah terhadap dirinya.

\section{Karakteristik Ekstrovert}

Hasil wawancara cara yang dilakukan dengan enam orang remaja putri yang mengalami kehamilan yang tidak diinginkan, diketahui ke empat remaja putri yang terbuka dalam menceritakan keluhan yang dialami selama kehamilannya. Dari data wawancara terhadap Ny.K, diperoleh hasil bahwa Ny. K memiliki karakteristik ekstrovert dalam menceritakan keluhan yang dialami pada saat kehamilan, karena terlihat nara sumber sangat terbuka cerita tentang keluhan yang dialami pada saat itu dan tidak terbata bata dalam menceritakannya.

Dari hasil wawancara terhadap Ny.V, Ny.G dan Ny.F, diperoleh hasil bahwa nara sumber ke tiganya memiliki karakteristik ekstrovert dalam menjawab pertanyaan tentang keluhan yang dirasakan pada saat kehamilan. Karena nara sumber sangat nyaman dalam menjawab pertanyaan tersebut dan tidak ada yang ditutupi.

Hasil wawancara mengenai berapa kali pergi kerumah bidan dan dengan siapa pergi periksa kehamilan diketahui ada lima remaja putri yang terbuka dalam menceritakan hal tersebut. Dari hasil wawancara terhadap Ny.A, Ny.R, Ny.V, Ny.G dan Ny.F, diperoleh hasil bahwa keempat remaja putri memiliki karakteristik ekstrovert dalam menceritakan berapa kali pergi kerumah bidan dan dengan siapa pergi periksa kehamilan tersebut. Ini dikarenakan narasumber dengan spontan menjawab pertanyaan yang diberikan dan tidak terbata-bata dalam menjawab pertanyaan tersebut.
Hasil wawancara mengenai pola makan pada saat kehamilan, diketahui ke enam remaja putri yang mengalami kehamilan yang tidak diinginkan terbuka dalam menceritakan hal tersebut. Karena terlihat nara sumber nyaman dalam menjawab pertanyaan yang diberikan. Dari hasil wawancara terhadap ke enam remaja putri, diperoleh hasil bahwa keenam remaja putri tersebut memiliki karakteristik ekstrovert dalam menjawab pertanyaan bagaimana pola makan pada saat kehamilan.

Hasil wawancara mengenai bagaimana aktifitas pekerjaan rumah pada saat kehamilan, dari enam orang remaja putri yang mengalami kehamilan yang tidak diinginkan diketahui ke enam orang remaja putri tersebut terbuka dalam menjawab pertanyaan.

Menurut teori yang terdapat ditinjauan pustaka, karakter ekstrovert adalah karakteristik berdasarkan psikologis atau tingkah laku dimana orang dengan kepribadian ini kalau merasa tertekan akan menggabungkan diri diantara orang banyak sehingga individualitasnya berkurang. Ia pemarah dan memilih pekerjaan-pekerjaan seperti pedagang, pekerja sosial, juru bicara dan semacamnya yaitu pekerjaan-pekerjaan yang banyak melibatkan orang-orang (Wirawan, 2000;82-84)

Berdasarkan hasil penelitian dan teori yang didapat ditinjauan pustaka dapat diketahui bahwa remaja putri yang mengalami kehamilan yang tidak diinginkan memiliki karakter terbuka dalam menceritakan keluhan pada saat kehamilan, apakah pernah periksa kerumah bidan, berapa kali dan dengan siapa pergi periksa, bagaimana pola makan pada saat kehamilan dan bagaimana aktivitas dan pekerjaan rumah apa dikerjakan sendiri atau dibantu dengan orang lain.

Oleh karena itu, peneliti menganalisis bahwasanya faktor yang mempengaruhi remaja putri yang mengalami kehamilan yang tidak diinginkan bersikap terbuka karena remaja tersebut ingin membagikan pengalamannya supaya tidak terjadi lagi 
kehamilan yang tidak diinginkan pada remaja lain.

\section{Karakteristik Ambivert}

Hasil wawancara cara yang dilakukan dengan 6 orang remaja putri yang mengalami kehamilan yang tidak diinginkan, diketahui tidak ada remaja putri yang mempunyai karakteristik ambivert yaitu campuran karakter introvert dan ekstrovert dalam menjawab pertanyaan yang diberikan.

\section{SIMPULAN}

Berdasarkan hasil penelitian remaja putri yang mengalami kehamilan yang tidak diinginkan di nagari Koto Baru Simalanggang Kecamatan Payakumbuh memiliki karakteristik introvert dalam menanggapi pertanyaan tentang siapa yang pertama kali mengetahui kehamilan dan tanggapan orang tersebut, perasaan saat mengetahui kehamilan, keluhan pada saat kehamilan, dan pernahkah pergi periksa kerumah bidan, berapa kali dan dengan siapa pergi periksa kehamilan, pola makan pada saat hamil dan aktifitas serta pekerjaan rumah yang dikerjakan sendiri atau dibantu oleh orang lain. Sedangkan remaja putri yang memiliki karakteristik ekstrovert dalam menanggapi pertanyaan keluhan pada saat kehamilan, pernahkah pergi periksa kerumah bidan, berapa kali dan dengan siapa pergi periksa kehamilan, pola makan pada saat kehamilan dan aktifitas serta pekerjaan rumah yang dikerjakan sendiri atau dibantu orang lain. Tidak ada remaja putri yang mengalami kehamilan yang tidak diinginkan memiliki karakteristik ambivert. Diharapkan kepada tenaga kesehatan agar dapat memberikan pendidikan seks dini pada remaja agar kejadian kehamilan yang tidak diinginkan tidak terulang kembali. Selanjutnya ucapan terimakasih penulis terhadap setiap pihak yang telah membantu kelancaran penelitian ini. Terimakasih kepada bidan wilayah, pejabat kantor kenagarian Koto Baru Simalanggang Kecamatan Payakumbuh dan seterusnya terhadap temanteman sejawat yang tidak dapat penulis sebutkan satu persatu.

\section{DAFTAR PUSTAKA}

Dianawati,Ajen. 2006. Pendidikan Seks Untuk Remaja. Depok:Kawan Pustaka

Emzir. 2012. Metodologi Penelitian Pendidikan : Kuantitatif dan Kualitatif. Jakarta:RajaGrafindo Persada

Gunawan, Arif. 2011. Remaja dan Permasalahannya. Yogyakarta:Hanggar Kreator.

Hurlock, Elizabeth. 2008. Psikologi Perkembangan. Jakarta: Erlangga

Kusmiran, Eni. 2011. Kesehatan Reproduksi Remaja dan Wanita. Jakarta : Salemba Medika

Kartono, Kartini. 2006. Psikologi Wanita 1. Jakarta:Mandar Maju

Kartono, Kartini. 2006. Psikologi Wanita. Jakarta:Mandar Maju

Lubis, Nova Julianti 2013. Hubungan Pengetahuan Remaja Putri Kelas X, XI dan XII terhadap Kerentanan Kejadian Hamil di Luar Nikah di SMAN 4 Bukittinggi tahun 2012. Di unduh di. http://njuliyanti.blogspot.co.id/2013/05/hubungan-pengetahuan-remajaputri.html tanggal 20 Desember 2013

Puskesmas Koto Baru Simalanggang Kecamatan payakumbuh. 2013. Laporan PKPR

Saryono. Dwi, Anggraeni, Mekar. 2011. Metodologi Penelitian Kualitatif. Yogyakarta: Nuha Medika

Sarwono, Sarlito W. 2012. Psikologi Remaja. Jakarta:RajaGrafindo Persada.

Sarwono. 2009. Ilmu Kebidanan. Jakarta: Yayasan Bina Pustaka Sarwono Prawirahardjo

Sastroasmoro, Sudigdo. 2011. Dasar-dasar Metodologi Penelitian Klinis. Jakarta: CV Sagung Seto 
Sugiyono. 2012. Metodologi Penelitian Pendidikan. Bandung: Alfabeta

Supraktiknya. A. 2006. Psikologi Kepribadian 3 Teori- Teori Sifat dan Behavioristik. Yogyakarta: Kanisius

Wirawan, Sarwono, Sarlito.2000. Pengantar Umum Psikologi. Jakarta: PT Bulan Bintang 